\title{
STRUCTURAL CHANGES OF LONG TUBULAR BONES OF MATURE RATS UNDER THE HYPERGLYCEMIA
}

DOI: 10.36740/WLek202109105

\author{
Alina 0. Ponyrko, Valentyna I. Bumeister, Serhii M. Dmytruk, Olha S. Yarmolenko, Tetiana P. Teslyk, \\ Tetiana V. Riabenko, Iryna Shkolna \\ SUMY STATE UNIVERSITY, SUMY, UKRAINE
}

\begin{abstract}
The aim: To evaluate morphological changes in long tubular bones of mature rats under the influence of experimental hyperglycemia. Materials and methods: The study was conducted on 140 nonlinear white male rats divided into two groups. The experimental group included rats that were introduced into a state of hyperglycemia by a single intraperitoneal injection of an alloxan dihydrate solution at a dose of $150 \mathrm{mg} / \mathrm{kg}$ body weight in $0.9 \%$ sodium chloride. The control group included rats that were injected with a similar volume of $0.9 \%$ sodium chloride one time intraperitoneally. The animals were taken out of the experiment on the $2^{\text {nd }}, 30^{\text {th }}, 60^{\text {th }}$, $90^{\text {th }}, 120^{\text {th }}, 150^{\text {th }}$ and $180^{\text {th }}$ day. Right and left femur and humerus were studied by morphometric and histological methods.

Results: Under conditions of prolonged uncontrolled hyperglycemia in mature rats, there is a slowdown in the growth rate of length and thickness of femur and humerus. This is indicated by a significant decrease in the length of bone and its diaphyses, as well as by a decrease in the cross-sectional area of the diaphysis, the width of the proximal and distal epiphyses, starting from 120 and 90 days of the experiment, respectively. The relative area of trabecular tissue, thickness of trabeculae and epiphyseal cartilage decreases in comparison with animals of the control group. The diameter of osteons and their channels increases in cortical tissue. Changes in the microarchitecture of the trabecular and cortical compartments of femur and humerus under conditions of hyperglycemia are similar and are characterized by a reduced bone mass, bone disorder progression and remodeling disorders.

Conclusions: Prolonged uncontrolled experimental hyperglycemia leads to slow growth of femur and humerus in mature rats, which is accompanied by an increase in microarchitecture disorder of the trabecular and cortical compartments, causing miniaturization of bones and, consequently, violation of their biomechanical properties and increased risk of fractures.
\end{abstract}

KEY WORDS: hyperglycemia, tubular bones, microarchitecture

Wiad Lek. 2021;74(9 p.l):2052-2059

\section{INTRODUCTION}

Hyperglycemia is one of the main factors that leads to the accumulation of end products of collagen glycation and, along with oxidative stress and systemic inflammation, determines the features of osteogenesis and bone remodeling in diabetes mellitus (DM). A direct or indirect consequence of long-term uncontrolled hyperglycemia is a decrease in bone mass and a significant increase in the risk of fractures, including long tubular bones, which is recognized as a proven complication of DM on a skeleton. The results of epidemiological studies indicate a steady trend to increase the number of fractures of various segments of long tubular bones in people with $\mathrm{DM}$, which causes increasing socio-economic damage and is a real challenge to modern health care. [1-4].

Metabolic disorders associated with both insulin deficiency and insulin resistance adversely affect bone health, leading to corresponding violations of their biomechanical properties in DM type I and DM type II [1,5].

Despite the almost 100-year history of the study of the problem and the significance of the results of clinical trials, some aspects of the pathomorphology and pathophysiology of diabetic bone disease are not fully clarified [6-8].
The question of the ratio of diabetic disorders of the cortical and trabecular components of the bone matrix (decrease in the number of trabeculae and increase in trabecular separation in the tubular bones, decrease in the thickness of the growth plate and cortical bone in general, etc., which cause a decrease in bone mass and bone quality) continues to be actively discussed. Differences in the risk of fractures in DM type I and DM type II, as well as in men and women, need to be explained $[9,10]$.

To date, there is no convincing theory to explain the complex mechanism of DM's impact on bone health. Significant difficulties are the separation of the effects of individual factors in this pathological continuum. The reliable predictor of fracture in such patients is still uncertain. Also, the evidence base for the treatment of complications of DM on the skeleton is imperfect [11-13]. In view of this, researches on the modeling of hyperglycemia in animals to study the pathomorphological basis of the development of diabetic bone disease can be considered quite relevant, as they provide significant information to clarify the mechanism of DM impact on the skeletal system and individual parts of different bones $[3,14,15]$. 


\section{THE AIM}

The aim of our study is to evaluate structural changes of long tubular bones of mature rats under the experimental hyperglycemia.

\section{MATERIALS AND METHODS}

The study was conducted at the Center for Morphological Research of the Medical Institute of Sumy State University on 140 mature nonlinear laboratory male rats. Animals were kept in standard vivarium conditions and were involved in the experiment in compliance with the requirements of the European Convention on the protection of vertebrate animals used for experimental and other scientific purposes (Strasbourg, France, 1986).

Experimental animals were randomly divided into two groups: group I - experimental $(n=70)$, group II control $(\mathrm{n}=70)$. After 10 hours of fasting animals of group I were simulated chronic hyperglycemia by a single intraperitoneal injection of an alloxan dihydrate solution (LaChema, Czech Republic) at a dose of $150 \mathrm{mg} / \mathrm{kg}$ body weight in $0.9 \%$ sodium chloride. According to the duration of chronic hyperglycemia, group I was divided into 7 subgroups (10 animals in each). Taking into account the age-related growth of the rats skeleton, animals of group II were also divided into 7 subgroups, according to the distribution of the animals from group I. Group II animals were injected with a similar volume of $0.9 \%$ sodium chloride once intraperitoneally.

Blood glucose levels were determined by glucose oxidase method using diagnostic kits Glucose F (Philisit-Diagnostics, Ukraine). The presence of glucosuria was determined by the express method using CITOLAB G test strips (Pharmasco, Ukraine). The concentration of $\mathrm{HbAlc}$ in whole blood was determined on a biochemical analyzer GBG ChemWell 2910 (Awareness Technology, USA).

The animals were taken out of the experiment on the $2^{\text {nd }}, 30^{\text {th }}, 60^{\text {th }}, 90^{\text {th }}, 120^{\text {th }}, 150^{\text {th }}$ and $180^{\text {th }}$ day 10 individuals from each group by decapitation under light thiopental-sodium anesthesia. For the study we took right and left femur and humerus. Osteometry was performed using a caliper SHC-1 (accuracy class 2, measurement error $0.1 \mathrm{~mm}$ ) according to the method of W. Duerest (1926). We measured the maximum bone length, the largest width of the proximal and distal epiphyses, the largest length of the diaphysis. Histological samples of proximal epiphyses and middle parts of diaphyses were prepared by generally accepted method and stained with hematoxylin and eosin. We analyzed such morphometric parameters of trabecular bone tissue as: relative area of spongy bone tissue, width of bone trabeculae and width of epiphyseal cartilage; and such indicators of cortical bone tissue as: diaphysis area, osteon diameter, osteon channel diameter, as well as the presence and size of resorption gaps and cement lines.

We used the program Statistica v.10 («StatSoft Inc.», USA) for statistical processing of the study results. We performed a descriptive analysis of each sample based on Mean (M) and Standard Deviation (SD). We applied the nonparametric Mann-Whitney U-test to assess the differences between the independent samples according to the studied indicators. The difference at $p<0,05$ was considered significant.

\section{RESULTS}

On the $2^{\text {nd }}$ day after the injection of alloxan dihydrate there are symptoms of hyperglycemia: polydipsia, polyuria, glucosuria in animals of group I. The average serum glucose concentration is 4.9 times more than in the control group, the average $\mathrm{HbAlc}$ concentration is 1.5 times more, but is within the normal range (table I). Subsequently, up to $180^{\text {th }}$ days of the experiment, animals of group I persist with a hyperglycemia, glucosuria and a gradual increase in the concentration of HbAlc (a marker of the magnitude and duration of hyperglycemia). We also observe no weight gain, in contrast to group II animals. Indicators of carbohydrate metabolism in rats of group I show the presence of persistent uncontrolled hyperglycemia, and their dynamics during the experiment reflects the features of compensatory-adaptive changes in animals under these conditions.

According to osteometry, the linear growth rates of the femur of both group I and II animals increase most

Table I. Dynamics of body weight and carbohydrate metabolism indicators in the blood of experimental animals

\begin{tabular}{ccccccc}
\hline $\begin{array}{c}\text { Week of } \\
\text { experiment }\end{array}$ & $\begin{array}{c}\text { Body } \\
\text { weight, } \mathbf{g}\end{array}$ & $\begin{array}{c}\text { Glucose, } \\
\mathbf{m m o l} / \mathbf{L}\end{array}$ & $\begin{array}{c}\text { HbA1c, } \\
\mathbf{\%}\end{array}$ & $\begin{array}{c}\text { Body } \\
\text { weight, } \mathbf{g}\end{array}$ & $\begin{array}{c}\text { Glucose, } \\
\mathbf{m m o l} / \mathbf{L}\end{array}$ & $\begin{array}{c}\text { HbA1c, } \\
\%\end{array}$ \\
\hline 2 & $186,2 \pm 13,2$ & $17,1 \pm 1,1$ & $6,1 \pm 0,2$ & $191,7 \pm 11,7$ & $3,5 \pm 0,1$ & $4,1 \pm 0,1$ \\
\hline 30 & $146,6 \pm 15,1$ & $14,8 \pm 1,3$ & $6,3 \pm 0,1$ & $193,2 \pm 14,5$ & $3,5 \pm 0,1$ & $4,0 \pm 0,1$ \\
\hline 60 & $161,3 \pm 12,6$ & $12,3 \pm 0,8$ & $7,1 \pm 0,3$ & $194,1 \pm 13,8$ & $6,0 \pm 0,1$ & $4,5 \pm 0,1$ \\
\hline 90 & $169,5 \pm 17,3$ & $10,2 \pm 1,2$ & $8,4 \pm 0,1$ & $198,5 \pm 10,6$ & $6,3 \pm 0,1$ & $5,1 \pm 0,1$ \\
\hline 120 & $168,2 \pm 25,2$ & $13,5 \pm 1,0$ & $9,1 \pm 0,1$ & $200,7 \pm 12,1$ & $6,5 \pm 0,1$ & $5,0 \pm 0,1$ \\
\hline 150 & $160,3 \pm 16,4$ & $12,0 \pm 1,3$ & $9,6 \pm 0,1$ & $204,2 \pm 8,9$ & $6,6 \pm 0,1$ & $4,9 \pm 0,1$ \\
\hline 180 & $167,2 \pm 21,3$ & $11,3 \pm 1,1$ & $9,9 \pm 0,1$ & $207,2 \pm 12,3$ & $6,6 \pm 0,1$ & $5,2 \pm 0,1$ \\
\hline
\end{tabular}

Note: the date are represented as Mean \pm SD (Standard Deviation), $\mathrm{p}<0,05$ 


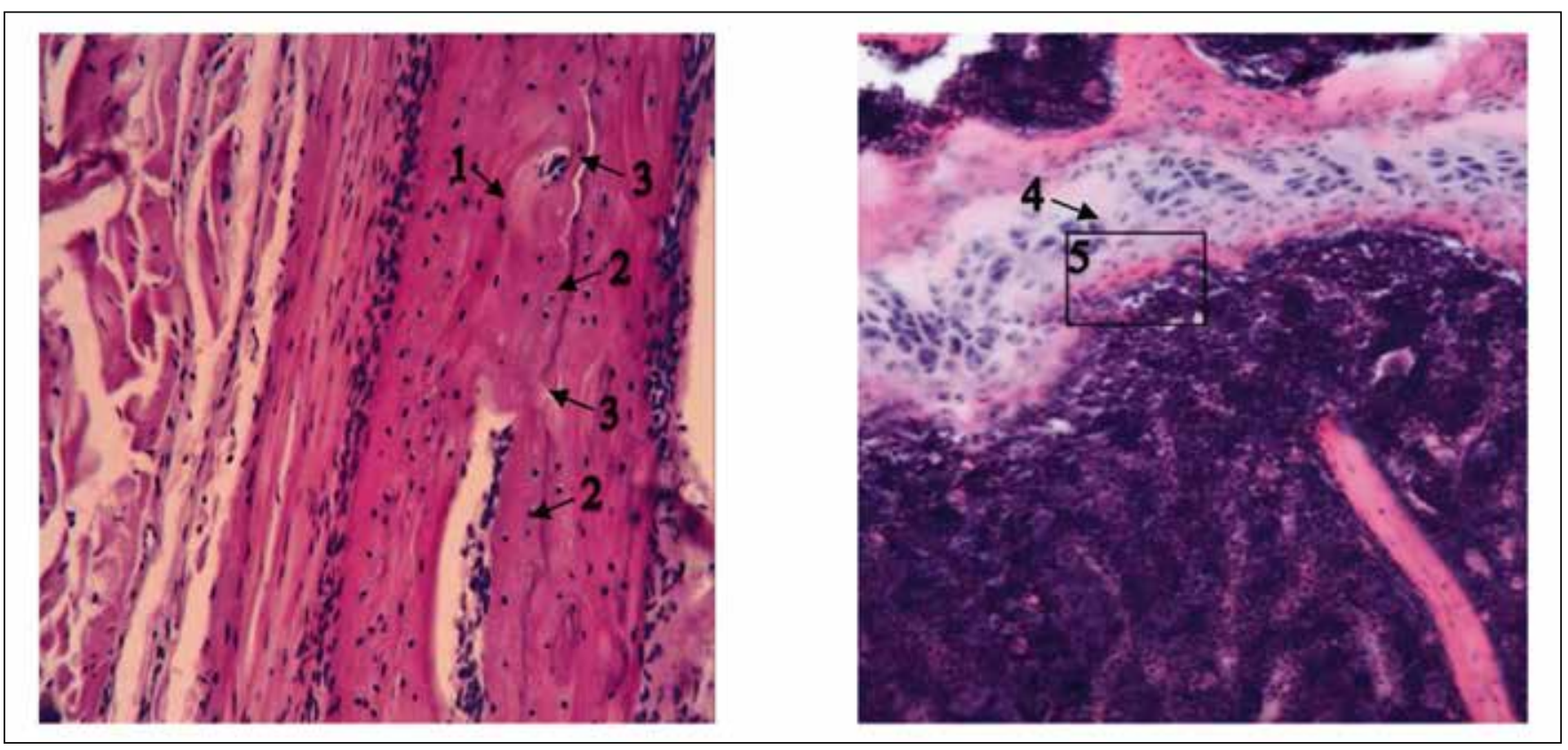

Fig. 1. The fragment of the mature rat's femur diaphysis on the 30th day after alloxan injection.

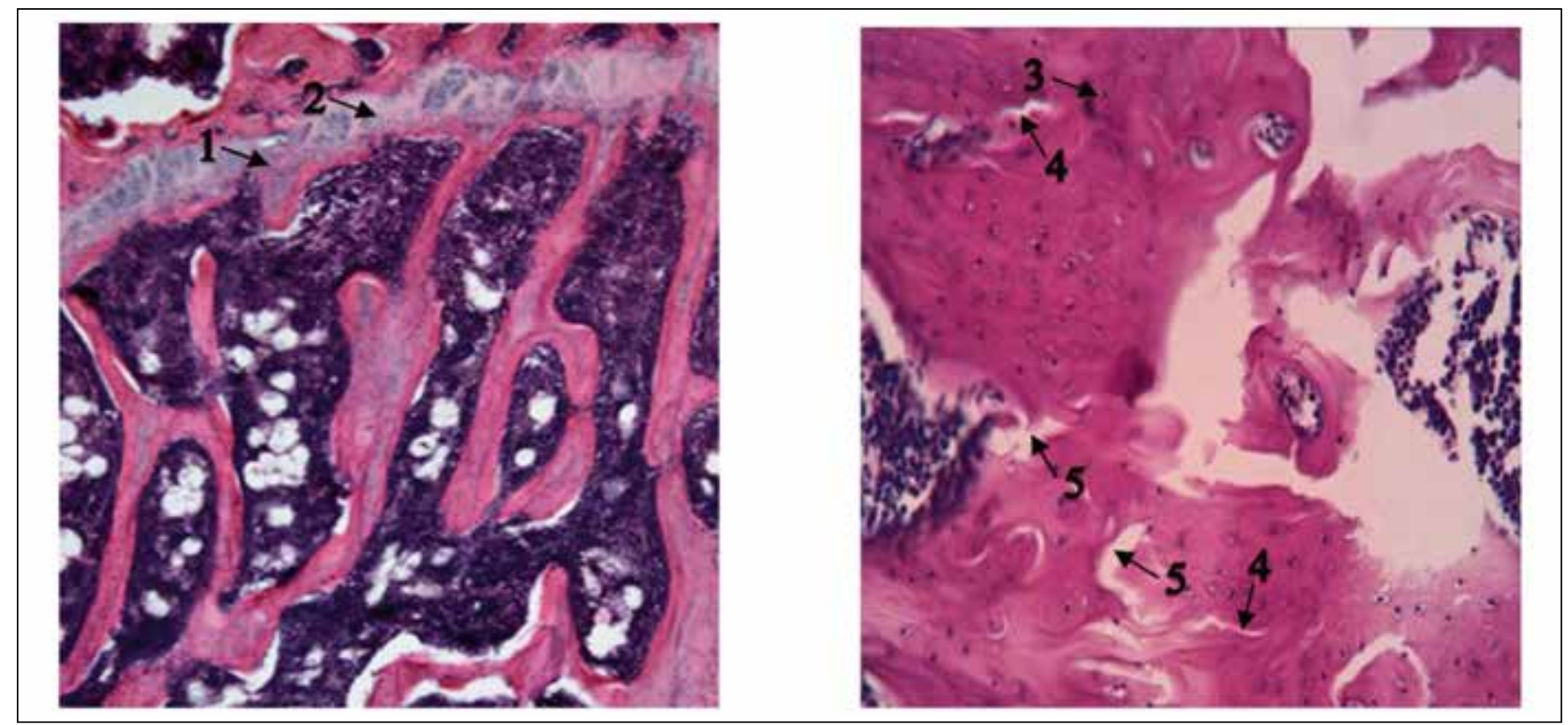

Fig. 2. The fragment of the mature rat's femur distal epiphysis on the 120th day after alloxan injection.

intensively up to $120^{\text {th }}$ day of the experiment, the humerus - up to $90^{\text {th }}$ day of the experiment (table II). However, on the $120^{\text {th }}$ day of the experiment, the average length of the femur in animals of the experimental group is significantly less than that in animals of the control group $(2.1 \%)$. This tendency to slow down the growth of femur in group I, compared with group II, persists until the $180^{\text {th }}$ day of the experiment. As a result, on the $180^{\text {th }}$ day of the experiment, the overall growth rate of the femur in group I is $25.7 \%$ while there is $27.3 \%$ in group II. Similar differences are found for the average length of the humerus in group I and group II, but starting from the $90^{\text {th }}$ day of the experiment. On the $180^{\text {th }}$ day of the experiment, the total growth rate of the humerus is $30.8 \%$ in group I and $35.9 \%$ in group II.

During the experiment, changes in the length of the diaphysis of femur and humerus in group I and group II correspond to the changes described for bone length. Namely, on the $180^{\text {th }}$ day of the experiment, the average length of the femur and humerus diaphysis in group I increases by $20.1 \%$ and $20.6 \%$, respectively, while in group II - by $23.4 \%$ and $32.6 \%$ respectively.

The average growth rates of the femur proximal and distal epiphyses width on the $180^{\text {th }}$ day of the experiment are $33.6 \%$ and $34.6 \%$, respectively, in group I, compared with $39.0 \%$ and $42.0 \%$, respectively, in group II. The average 
Table II. Osteometric indicators of the femur and humerus

\begin{tabular}{|c|c|c|c|c|c|c|c|c|}
\hline \multirow{3}{*}{ 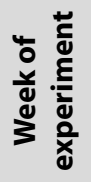 } & \multicolumn{2}{|c|}{$\begin{array}{c}\text { Bone length, } \\
\mathrm{mm}\end{array}$} & \multicolumn{2}{|c|}{$\begin{array}{l}\text { Proximal epiphysis width, } \\
\text { mm }\end{array}$} & \multicolumn{2}{|c|}{$\begin{array}{l}\text { Distal epiphysis width, } \\
\text { mm }\end{array}$} & \multicolumn{2}{|c|}{$\begin{array}{l}\text { Diaphysis length, } \\
\text { mm }\end{array}$} \\
\hline & \multicolumn{8}{|c|}{ Group ( $n=70$ for both groups) } \\
\hline & $\mathbf{I}$ & II & $\mathbf{I}$ & II & $\mathbf{I}$ & II & $\mathbf{I}$ & II \\
\hline & \multicolumn{8}{|c|}{ The femur } \\
\hline \multirow{2}{*}{2} & 29,98 & 30,32 & 3,18 & 3,36 & 3,24 & 3,50 & 19,01 & 19,20 \\
\hline & $\pm 1,25$ & $\pm 1,16$ & $\pm 0,04$ & $\pm 0,07$ & $\pm 0,15$ & $\pm 0,12$ & $\pm 1,12$ & $\pm 1,30$ \\
\hline \multirow{2}{*}{30} & 30,04 & 33,41 & 3,24 & 3,42 & 3,32 & 3,54 & 19,06 & 19,30 \\
\hline & $\pm 2,20$ & $\pm 1,96$ & $\pm 0,11$ & $\pm 0,10$ & $\pm 0,14$ & $\pm 0,11$ & $\pm 0,95$ & $\pm 1,41$ \\
\hline \multirow{2}{*}{60} & 31,17 & 31,70 & 3,36 & 3,57 & 3,45 & 3,68 & 19,15 & 19,57 \\
\hline & $\pm 1,48$ & $\pm 1,72$ & $\pm 0,12$ & $\pm 0,10$ & $\pm 0,08$ & $\pm 0,07$ & $\pm 0,91$ & $\pm 0,90$ \\
\hline \multirow{2}{*}{90} & 33,44 & 34,10 & 3,55 & 3,80 & 3,62 & 3,97 & 19,35 & 19,85 \\
\hline & $\pm 1,69$ & $\pm 1,28$ & $\pm 0,13$ & $\pm 0,11$ & $\pm 0,08$ & $\pm 0,10$ & $\pm 1,73$ & $\pm 1,29$ \\
\hline \multirow{2}{*}{120} & 35,65 & 36,42 & 4,10 & 4,40 & 4,24 & 4,67 & 21,40 & 22,09 \\
\hline & $\pm 1,98^{*}$ & $\pm 2,50$ & $\pm 0,12^{*}$ & $\pm 0,10$ & $\pm 0,12^{*}$ & $\pm 0,17$ & $\pm 1,65^{*}$ & $\pm 1,28$ \\
\hline \multirow{2}{*}{150} & 36,56 & 37,40 & 4,18 & 4,58 & 4,30 & 4,85 & 22,47 & 23,16 \\
\hline & $\pm 2,11^{*}$ & $\pm 1,88$ & $\pm 0,07^{*}$ & $\pm 0,10$ & $\pm 0,08^{*}$ & $\pm 0,09$ & $\pm 1,24^{*}$ & $\pm 1,09$ \\
\hline \multirow{3}{*}{180} & 37,67 & 38,60 & 4,25 & 4,67 & 4,36 & 5,97 & 23,75 & 24,61 \\
\hline & $\pm 1,73^{*}$ & $\pm 1,49$ & $\pm 0,11^{*}$ & $\pm 0,12$ & $\pm 0,10^{*}$ & $\pm 0,13$ & $\pm 0,95^{*}$ & $\pm 1,10$ \\
\hline & \multicolumn{8}{|c|}{ The humerus } \\
\hline \multirow{2}{*}{2} & 21,31 & 21,61 & 2,65 & 2,85 & 3,69 & 4,02 & 13,41 & 13,65 \\
\hline & $\pm 0,57$ & $\pm 0,70$ & $\pm 0,10$ & $\pm 0,03$ & $\pm 0,12$ & $\pm 0,10$ & $\pm 1,05$ & $\pm 0,95$ \\
\hline \multirow{2}{*}{30} & 21,40 & 21,70 & 2,71 & 2,90 & 3,79 & 4,06 & 13,49 & 13,71 \\
\hline & $\pm 1,21$ & $\pm 0,93$ & $\pm 0,11$ & $\pm 0,13$ & $\pm 0,21$ & $\pm 0,11$ & $\pm 1,91$ & $\pm 1,09$ \\
\hline \multirow{2}{*}{60} & 21,47 & 23,41 & 2,84 & 3,05 & 3,90 & 4,19 & 13,62 & 13,90 \\
\hline & $\pm 2,12$ & $\pm 1,29$ & $\pm 0,17$ & $\pm 0,04$ & $\pm 0,09$ & $\pm 0,08$ & $\pm 1,16$ & $\pm 1,40$ \\
\hline \multirow{2}{*}{90} & 23,94 & 25,03 & 2,97 & 3,20 & 3,97 & 4,31 & 13,90 & 14,47 \\
\hline & $\pm 1,65^{*}$ & $\pm 1,73$ & $\pm 0,05^{*}$ & $\pm 0,09$ & $\pm 0,09^{*}$ & $\pm 0,08$ & $\pm 1,19^{*}$ & $\pm 1,52$ \\
\hline \multirow{2}{*}{120} & 25,83 & 27,06 & 3,49 & 3,78 & 4,46 & 4,86 & 15,55 & 16,23 \\
\hline & $\pm 1,31^{*}$ & $\pm 1,28$ & $\pm 0,06^{*}$ & $\pm 0,07$ & $\pm 0,11^{*}$ & $\pm 0,13$ & $\pm 2,20^{*}$ & $\pm 1,79$ \\
\hline \multirow{2}{*}{150} & 26,92 & 28,30 & 3,55 & 3,86 & 4,68 & 5,11 & 16,43 & 17,20 \\
\hline & $\pm 2,11^{*}$ & $\pm 1,39$ & $\pm 0,19^{*}$ & $\pm 0,21$ & $\pm 0,17^{*}$ & $\pm 0,20$ & $\pm 1,28^{*}$ & $\pm 1,43$ \\
\hline \multirow[b]{2}{*}{180} & 27,87 & 29,36 & 3,62 & 4,03 & 5,03 & 5,74 & 17,24 & 18,10 \\
\hline & $\pm 1,19^{*}$ & $\pm 1,42$ & $\pm 0,18^{*}$ & $\pm 0,04$ & $\pm 0,26^{*}$ & $\pm 0,12$ & $\pm 2,11^{*}$ & $\pm 1,67$ \\
\hline
\end{tabular}

Note: the date are represented as Mean \pm SD (Standard Deviation), ${ }^{*} \mathrm{p}<0,05$

growth rates of the humerus proximal and distal epiphyses width on the $180^{\text {th }}$ day of the experiment are $35.4 \%$ and $37.2 \%$, respectively, in group I, compared with $39.0 \%$ and $41.4 \%$, respectively, in group II.

On the $30^{\text {th }}$ day of the experiment, the relative area indicators of trabecular bone tissue, the bone trabeculae and epiphyseal cartilage width of the femur and the humerus are not differ significantly in animals of both groups (table III). But, according to histological examination, a number of structural changes are revealed in the corresponding loci of the bones in group I. In the area of primary spongiosis, there is a partial absence of trabeculae, and the newly formed trabeculae are unevenly distributed, short, thin and, in some zones, do not form connections with each other. A large number of capillaries and preosteoblasts are located between them due to the formation of bone tissue in this area (fig. 1b). A small density of trabeculae is visualized in the area of secondary spongiosis. They are located at a distance from each other, and do not form a trabecular meshwork. There is also an almost complete lack of connections between the trabeculae and cortical tissue.

In the structure of the epiphyseal cartilage of both the femur and humerus are small areas of hypertrophy. In this case, the proliferation zone is the largest in height and is formed by columns of chondrocytes oriented parallel to the bone central axis. The cells have a squamous or trigonal shape with basophilic nuclei and cytoplasm, their size increases as they approach the hypertrophy zone. In the hypertrophy area, the cytoplasm of cells is vacuolated, and the basophilic nucleus often loses clear contours. There is a decrease in the height of proliferative columns, and in the vast majority of proliferative columns there are empty areas without cells. 
Table III. Morphometric indicators of the trabecular bone of the femur and humerus

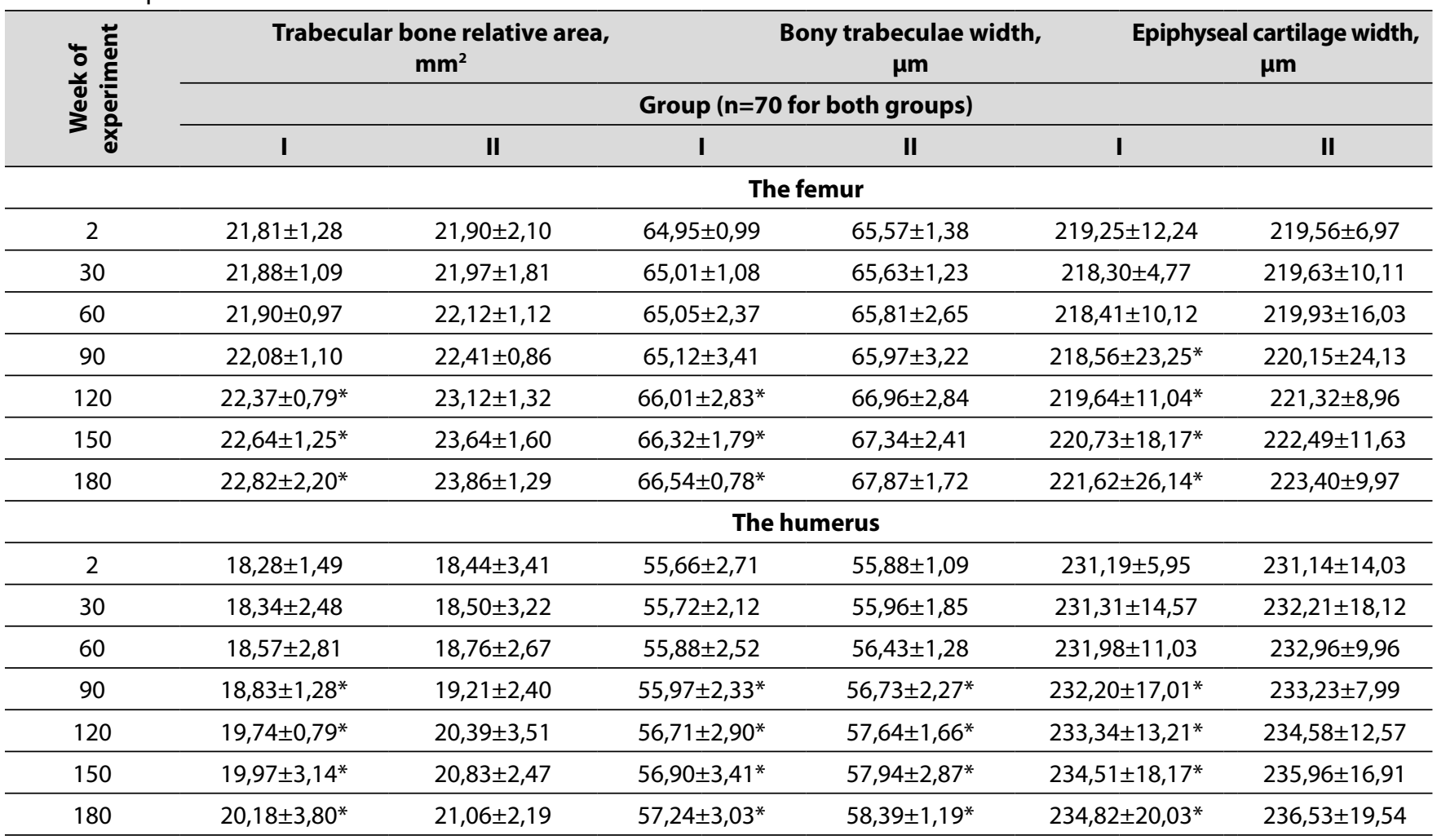

Note: the date are represented as Mean \pm SD (Standard Deviation), ${ }^{*} p<0,05$

Table IV. Morphometric indicators of the cortical bone of the femur and humerus

\begin{tabular}{|c|c|c|c|c|c|c|}
\hline \multirow{3}{*}{ 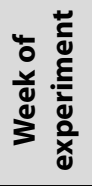 } & \multicolumn{2}{|c|}{$\begin{array}{l}\text { Diaphysis cross-section area, } \\
\qquad \mathbf{m m}^{2}\end{array}$} & \multicolumn{2}{|c|}{$\begin{array}{l}\text { Osteon diameter, } \\
\mu \mathrm{m}\end{array}$} & \multicolumn{2}{|c|}{$\begin{array}{c}\text { Osteon canal diameter, } \\
\mu \mathrm{m}\end{array}$} \\
\hline & \multicolumn{6}{|c|}{ Group ( $n=70$ for both groups) } \\
\hline & $\mathbf{I}$ & II & $\mathbf{I}$ & II & $\mathbf{I}$ & II \\
\hline & \multicolumn{6}{|c|}{ The femur } \\
\hline 2 & $5,04 \pm 0,09$ & $5,06 \pm 0,08$ & $30,11 \pm 1,21$ & $30,07 \pm 1,12$ & $11,07 \pm 1,09$ & $11,13 \pm 1,25$ \\
\hline 30 & $5,10 \pm 0,15$ & $5,35 \pm 0,21$ & $30,12 \pm 2,41$ & $30,09 \pm 0,79$ & $11,35 \pm 1,41$ & $11,17 \pm 1,47$ \\
\hline 60 & $5,54 \pm 0,07$ & $5,90 \pm 0,21$ & $30,64 \pm 0,96$ & $30,47 \pm 1,72$ & $11,72 \pm 1,15$ & $11,43 \pm 1,08$ \\
\hline 90 & $5,83 \pm 0,11^{*}$ & $6,48 \pm 0,14$ & $30,95 \pm 1,23$ & $30,74 \pm 1,90$ & $11,93 \pm 2,83$ & $11,60 \pm 1,61$ \\
\hline 120 & $6,74 \pm 0,15^{*}$ & $7,31 \pm 0,21$ & $31,84 \pm 2,42$ & $31,17 \pm 1,77$ & $12,81 \pm 1,44$ & $12,26 \pm 1,43$ \\
\hline 150 & $6,95 \pm 0,32^{*}$ & $7,86 \pm 0,12$ & $31,97 \pm 3,11$ & $31,58 \pm 1,64$ & $12,97 \pm 2,60$ & $12,53 \pm 1,92$ \\
\hline \multirow[t]{2}{*}{180} & $7,10 \pm 0,12^{*}$ & $8,03 \pm 0,17$ & $32,30 \pm 2,43^{*}$ & $31,84 \pm 1,35$ & $13,40 \pm 1,58^{*}$ & $12,81 \pm 1,67$ \\
\hline & \multicolumn{6}{|c|}{ The humerus } \\
\hline 2 & $4,51 \pm 0,11$ & $4,44 \pm 0,09$ & $21,14 \pm 1,27$ & $21,26 \pm 1,18$ & $8,28 \pm 0,14$ & $8,34 \pm 0,17$ \\
\hline 30 & $4,65 \pm 0,12$ & $4,93 \pm 0,23$ & $21,40 \pm 1,46$ & $21,23 \pm 1,15$ & $8,45 \pm 0,09$ & $8,40 \pm 0,07$ \\
\hline 60 & $4,87 \pm 0,09$ & $5,18 \pm 0,11$ & $21,60 \pm 2,44$ & $21,40 \pm 2,14$ & $8,53 \pm 0,15$ & $8,32 \pm 0,12$ \\
\hline 90 & $5,02 \pm 0,10^{*}$ & $5,56 \pm 0,07$ & $21,89 \pm 1,31$ & $21,67 \pm 1,81$ & $8,84 \pm 0,32$ & $8,60 \pm 0,24$ \\
\hline 120 & $5,96 \pm 0,03^{*}$ & $6,44 \pm 0,06$ & $22,93 \pm 2,12$ & $22,67 \pm 1,28$ & $9,81 \pm 0,14$ & $9,42 \pm 0,54$ \\
\hline 150 & $6,14 \pm 0,14^{*}$ & $6,85 \pm 0,05$ & $23,30 \pm 2,31$ & $22,95 \pm 0,93$ & $10,10 \pm 0,05$ & $9,90 \pm 0,12$ \\
\hline 180 & $6,35 \pm 0,07^{*}$ & $7,08 \pm 0,12$ & $23,45 \pm 2,40^{*}$ & $23,05 \pm 1,45$ & $10,20 \pm 0,15$ & $10,04 \pm 0,08$ \\
\hline
\end{tabular}

Note: the date are represented as Mean \pm SD (Standard Deviation), ${ }^{*} \mathrm{p}<0,05$

On the $120^{\text {th }}$ day of the experiment, the relative area value of the femur and humerus trabecular bone tissue is significantly smaller in group I compared with group II by $3.4 \%$ and $3.3 \%$, respectively. The average width of bone trabeculae is also significantly lower in group I: by $1.4 \%$ in the femur and by $1.6 \%$ in the humerus. The width of the 
epiphyseal cartilage is also significantly smaller in group I: by $0.8 \%$ in the femur and by $0.5 \%$ in the humerus.

On the $120^{\text {th }}$ day of the experiment, the structural changes in the trabecular bone tissue of the femur and humerus in group I differ in that in the area of primary spongiosis newly formed trabeculae are less densely placed than in previous terms $\left(30^{\text {th }}, 60^{\text {th }}\right.$, and $90^{\text {th }}$ day $)$, but are wider and connect with each other, forming a trabecular network. The trabeculae surface is covered with osteoblasts. Osteocytes in the matrix are unevenly distributed, their greater density is observed near the trabeculae surface, while in the middle part are cell-free areas. In the area of secondary spongiosis trabeculae are arranged more separately from each other, compared with the area of primary spongiosis (fig. 2a). Unmineralized areas are found in the central part of many trabeculae. Osteoblasts are identified on the surface of many trabeculae. The intertrabecular spaces are filled with red bone marrow with foci of yellow bone marrow, which indicates the degeneration of red bone marrow and the differentiation of mesenchymal cells instead of osteoblasts into adipocytes. There are also a small number of trabeculae located singly, without the formation of a trabecular network. Proliferative columns are often located singly, their height is heterogeneous. There is also disorientation of proliferative columns, in some areas of which cells are absent, indicating less proliferative activity.

Until the end of the experiment (180 days), the femur and humerus trabecular bone tissue indicators in group I remain significantly lower, compared with those in group II. In general, for the entire period of the experiment, the increase in the femur trabecular bone tissue relative area in group I is $4.6 \%$ and $10.4 \%$ - for the humerus, and in group II $-8.9 \%$ and $14.2 \%$, respectively. The trabeculae width in group I increases by $2.4 \%$ in the femur and by $2.8 \%$ - in the humerus, and in group II $-3.5 \%$ and $4.5 \%$. The increase in the epiphyseal cartilage thickness in group I slows down and is $0.9 \%$ in the femur, $1.6 \%$ in the humerus, while in group II $-1.7 \%$ and $2.3 \%$, respectively.

On the $180^{\text {th }}$ day of the experiment in both bones in group I animals in the primary spongiosis area is a large number of trabeculae that do not form a trabecular meshwork. In the secondary spongiosis area, the humerus and femur bone trabeculae are characterized by a chaotic cement lines, which indicates their active restructuring. Osteocytes are distributed unevenly, sometimes dead cells occur. In the group I femur and humerus epiphyseal cartilage there is the appearance of cartilage reduction areas with a corresponding cessation of growth processes in the bones. In these areas, there is a significant thinning of the surface area, which may indicate the inhibition of growth processes due to the lack of structures that are the source of cells for the intermediate zone. The cells of this zone are located mainly in the columns parallel to the bone central axis, but in certain areas form clusters similar to large isogenic groups characteristic of the articular cartilage intermediate zone. In such areas the matrix has an eosinophilic color, which is also typical for articular cartilage, not epiphyseal.
On the $30^{\text {th }}$ day of the experiment the average cross-sectional area of the diaphysis, the diameter of osteons and their channels in the studied bones are not differ significantly in group I and group II (table IV). In this case, there are weak signs of periosteal resorption in the cortical tissue of the humerus in group I. At the level of secondary spongiosis in the matrix of the cortex there are non-mineralized areas made of cartilaginous tissue, which indicates the loss of durable qualities of bone. In the structure of the diaphysis, both femur and humerus of animals with hyperglycemia, the presence of adhesive lines was observed, which indicates a delay in periosteal bone formation. Osteoclastic resorption cavities are also detected. There is the appearance of empty osteocyte lacunae, which probably indicates the death of osteocytes by apoptosis. In some areas, the cement line has an unstructured amorphous appearance (fig. 1a). The density of cortical tissue in such places is broken, as evidenced by the presence of cracks and crevices in it. There are also areas of resorption that are not filled with osteoblasts and osteocytes with fragmented nuclei (signs of apoptosis).

From the $90^{\text {th }}$ day until the end of the experiment, animals with hyperglycemia have significantly smaller cross-sectional areas of both the femur and humerus diaphyses, compared with those in the control group. On the $120^{\text {th }}$ day of the experiment this difference is $8.5 \%$ for the femur and $8.1 \%$ for the humerus. In terms of osteons diameter and their channels, there is no significant difference between animals of group I and group II.

In the group I femur and humerus cortical bone tissue on the $120^{\text {th }}$ day there are signs of periosteal resorption in the form of single resorption lacunae, but they are less pronounced, compared with earlier periods of observation. In the diaphyses there are single cavities of osteoclastic resorption in all layers of compact matter. There are single gaps between the outer and inner general plates. In some cases, the mosaic of calcification and reduction of remodeling cones is visualized (fig.2b).

On the $180^{\text {th }}$ day of the experiment, the average cross-sectional area of the femur and humerus diaphysis in group I is $13.1 \%$ and $11.5 \%$ lower, respectively, than in group II. In general, for the entire observation period, the increase in group I femur and humerus cross-sectional area is $40.9 \%$ (58.7\% in group II) and $40.8 \%$ (59.5\%), respectively. The diameters of the femur and humerus osteons and their channels are significantly higher in group I. During the entire observation period the average diameters of osteons in group I femur and humerus increases by $7.3 \%$ and $10.9 \%$, respectively, while in group II - by $5.9 \%$ and $8.4 \%$. Similar dynamics is established for indicators of diameters of both bones osteons channels. Thus, the increase in the animals with hyperglycemia average diameter of osteon channels in the femur and humerus occurs by $21.0 \%$ and $23.2 \%$, respectively, and in the control group $-15.1 \%$ and $20.2 \%$.

On the $180^{\text {th }}$ day of the experiment in the femur and humerus cortical tissue of group I there are similar to the previous observation period non-mineralized areas, as well as clear signs of periosteal resorption and a decrease 
in osteoblasts in the cambial layer of periosteum. In the layers of the outer and inner general plates there are resorption cavities and microcracks. Extended osteon channels are observed, which are much larger in comparison with those in group II.

\section{DISCUSSION}

This experimental study aims to establish the features of structural changes in the long tubular bones of mature rats under conditions of prolonged uncontrolled hyperglycemia.

The obtained data of the femur and humerus osteometry and the revealed pathomorphological changes in the trabecular and cortical tissues of the experimental animals long tubular bones indicate a slowdown in their growth and violation of their biomechanical properties. They confirm previous observations and supplement the accumulated information on the effects of prolonged uncontrolled hyperglycemia on the skeletal system in general and long tubular bones in particular. [1-4].

The retardation of growth and disturbance of rats long tubular bones remodeling noted in our research is obviously the result of a complex of negative factors influence among which insulin deficiency and a hyperglycemia are the basic defining a direction and features of the subsequent pathomorphological changes development. $[1,3,15]$.

The pathological remodeling of femur and humerus trabecular tissue of rats described by us conforms well with the experimental data obtained by T. Ahmad et al., J. Zhang et al., as well as with the results of clinical observations conducted by N. Abdalrahman et al. The mentioned authors note the loss of trabecular tissue, in particular in the composition of long tubular bones, under conditions of hyperglycemia, which leads to trabecular miniaturization and, accordingly, to an increased risk of periarticular fractures. $[6,14,16]$. In this context, we can agree with J. Starup-Linde, who considers that the assessment of bone's trabecular compartment may be one of the most valuable predictors of fractures in patients with DM, because, according to our data, pathomorphological disorders in trabecular tissue in particular of long tubular bones appear earlier and have a greater degree of severity, compared with violations in the cortical tissue microarchitecture [12].

Since the biomechanical properties of bones are determined by a set of interrelated factors, and as for the geometric structure, it is, among other things, the ratio of trabecular and cortical compartments, the study of structural features of cortical tissue under the hyperglycemia is no less important [12]. Our findings on slowing the increase in the length and thickness of the long tubular bones diaphyses and increasing the diameters of osteons and their channels, along with other morphological changes in the microarchitecture of the cortex are consistent with the data obtained by J. Zhang et al. and B. Ay et al. in animal model experiments, and also conform with the opinion of V. Shah et al., who in particular consider that cortical tissue undergoes very pronounced pathological changes in DM type I $[10,14,15]$.
As a result, it should be noted that the limitation of our study is the lack of data obtained by us to determine the diagnostically valuable morphological predictor of large tubular bones fractures under conditions of prolonged uncontrolled hyperglycemia. Based on this, we consider further studies of the structural features of long tubular bones' individual compartments in conditions of hyperglycemia with an emphasis on the search for such a predictor, the most promising in this particular direction.

\section{CONCLUSIONS}

Thus, in rats under conditions of prolonged (180 days) uncontrolled experimental hyperglycemia, there is a slowdown in the growth of the femur and humerus in both length and thickness with corresponding violations in the structure of trabecular and cortical tissues. Pathomorphological changes of trabecular tissue have a more pronounced degree and are characterized by a decrease in the growth of its relative area, and the structure itself is characterized by a smaller width of trabeculae, pathological reorganization of their architecture (increased disorder) and reduced proliferative activity of tissue. The growth of epiphyseal cartilage also slows down, which is the result of depletion of the pool of cells that provide it.

Under such conditions, pathomorphological changes in cortical tissue are expressed in the form of slowing down the increase in the length and thickness of the femur and humerus diaphyses, along with a tendency to increase the diameters of osteons and their channels. This also increases the disorder of cortical tissue, the morphological signs of periosteal resorption and decreases the proliferative activity of the tissue. In general, these pathomorphological changes lead to a violation of the biomechanical properties of the femur and humerus and, accordingly, to an increased risk of fractures.

\section{REFERENCES}

1. Jiao H., Xiao E., Graves D.T. Diabetes and its effect on bone and fracture healing. Curr Osteoporos Rep. 2015;13(5):327-335. doi: 10.1007/ s11914-015-0286-8.

2. Bonora E., DeFronzo R.A. Diabetes complications, comorbidities and related disorders. Cham: Springer Nature Switzerland; 2020, p. 724. doi: 10.1007/978-3-030-36694-0.

3. Yang J., Chen S., Zong Z. et al. The increase in bone resorption in early-stage type I diabetic mice is induced by RANKL secreted by increased bone marrow adipocytes. Biochemical and Biophysical Research Communications. 2020;525(2):433-439. doi: 10.1016/j. bbrc.2020.02.079.

4. Yau M., Robinson C., Sperling M.A. Diabetes mellitus and bone disorders. In: Zaidi M, ed. Encyclopedia of bone biology. San Diego: Elsevier Science Publishing Co Inc; 2020, 10-22. doi: 10.1016/B978-0-12-801238-3.11556-9.

5. Kalaitzoglou E., Popescu I., Bunn R.C. et al. Effects of type 1 diabetes on osteoblasts, osteocytes, and osteoclasts. Curr 0steoporos Rep. 2016;14(6):310-319. doi: 10.1007/s11914-016-0329-9.

6. Abdalrahman N., McComb C., Foster J.E. et al. Deficits in trabecular bone microarchitecture in young women with type 1 diabetes mellitus. Journal of Bone and Mineral Research. 2015;30(8):1386-1393. doi: 10.1002/jbmr.2465. 
7. Wang J.F., Lee M.S., Tsai T.L. et al. Bone Morphogenetic Protein-6 Attenuates Type 1 Diabetes Mellitus-Associated Bone Loss. Stem Cells Translational Medicine. 2019;522-534. doi:10.1002/sctm.18-0150.

8. Shah V.N., Joshee P., Sippl R. et al. Type 1 diabetes onset at young age is associated with compromised bone quality. Bone. Official Journal of the International Bone and Mineral Society. 2019;123:260-264. doi. org/10.1016/j.bone.2019.03.039.

9. Ma R., Wanga L., Zhao B. et al. Diabetes Perturbs Bone Microarchitecture and Bone Strength through Regulation of Sema3A/IGF-1/ $\beta$-Catenin in Rats. Cell Physiol Biochem. 2017;41:55-66. doi.org/10.1159/000455936.

10. Shah V.N., Carpenter R.D., Ferguson V.L. et al. Bone health in type 1 diabetes. Curr Opin Endocrinol Diabetes Obes. 2018;25(4):231-236. doi: 10.1097/MED.0000000000000421.

11. Schacter G.I., LeslieW.D. Diabetes and bone disease. Endocrinology and Metabolism Clinics of North America. 2017;46(1):63-85. doi: 10.1016/j. ecl.2016.09.010.

12. Starup-Linde J., Gregersen S. Bone and diabetes. In: Bonora E, DeFronzo RA, eds. Diabetes Complications, Comorbidities and Related Disorders, Endocrinology. Cham: Springer; 2019, 411-436 p. doi: 10.1007/978-3319-44433-8_13.

13. Murray C.E., Coleman C.M. Impact of diabetes mellitus on bone health. Int. J. Mol. Sci. 2019;20:4873. doi: 10.3390/ijms20194873.

14. Zhang J., Chen X., Chen B. et al. Tetrahydroxy stilbene glucoside protected against diabetes-induced osteoporosis in mice with streptozotocininduced hyperglycemia. Phytotherapy Research. 2018;33:1-10. doi: 10.1002/ptr.6240.

15. Ay B., Parolia K., Liddell R.S. et al. Hyperglycemia compromises rat cortical bone by increasing osteocyte lacunar density and decreasing vascular canal volume. Commun Biol. 2020;3,20(2020). doi:10.1038/ s42003-019-0747-1.

16. Ahmad T., Ohlsson C., Saaf M. et al. Skeletal changes in type-2 diabetic Goto-Kakizaki rats. Journal of Endocrinology. 2003;178:111-116. doi: 10.1677/joe.0.1780111.
The study was performed within the planned research topic "Morphofunctional aspects of homeostasis", state registration number $0118 U 006611$.

\section{ORCID and contributionship:}

Alina O. Ponyrko: 0000-0002-1799-7789 ${ }^{D}$

Valentyna I. Bumeister: 0000-0001-8604-4458 ${ }^{F}$

Serhii M. Dmytruk: 0000-0001-6434-2817 ${ }^{E}$

Olha S. Yarmolenko: 0000-0002-7872-2308 ${ }^{\mathrm{A}}$

Tetiana P. Teslyk: 0000-002-5832-7415 ${ }^{\mathrm{C}}$

Tetiana V. Riabenko: 0000-0003-2740-389X ${ }^{B}$

Iryna Shkolna: 0000-0001-6756-0158 ${ }^{B}$

\section{Conflict of interest:}

The Authors declare no conflict of interest.

\section{CORRESPONDING AUTHOR \\ Alina 0. Ponyrko \\ Medical Institute, Sumy State University \\ 31 Sanatorna st., 40018 Sumy, Ukraine \\ tel: +380661531516 \\ e-mail:ponyrkoalina123@gmail.com}

Received: 26.08 .2020

Accepted: 02.06 .2021

A - Work concept and design, B - Data collection and analysis, C - Responsibility for statistical analysis,

D-Writing the article, $\mathbf{E}$-Critical review, $\mathbf{F}$ - Final approval of the article 